\title{
Sterilization \& Infection Control in Orthodontic Clinic: A Literature Review
}

\author{
Sharath Kumar Shetty ${ }^{1}$, Mahesh Kumar Y², Lekshmi G Vijayan ${ }^{3 *}$, Vijayananda K Madhur ${ }^{4}$
}

\author{
${ }^{1}$ Professor \& HOD, Department of Orthodontics and Dentofacial Orthopaedics, K. V. G. Dental College and Hospital, Sullia, Karnataka, India \\ ${ }^{2}$ Professor, Department of Orthodontics and Dentofacial Orthopaedics, K. V. G. Dental College and Hospital, Sullia, Karnataka, India \\ ${ }^{3}$ Post Graduate Student, Department of Orthodontics and Dentofacial Orthopaedics, K. V. G. Dental College and Hospital, Sullia, Karnataka, India \\ ${ }^{4}$ Reader, Department of Orthodontics and Dentofacial Orthopaedics, K. V. G. Dental College and Hospital, Sullia, Karnataka, India
}

*Corresponding author: Lekshmi G Vijayan

\section{Abstract}

Corona virus disease 2019 (COVID-19), is a novel disease of global concern and has evolved rapidly into a public health crisis. The infection is highly contagious, with disease transmission reported from asymptomatic carriers, including children. So in todays orthodontic practice, disease control must undergo major reevaluation and restructuring and must be given prime importance. Effective infection control must be a routine component of professional activity. Thorough understanding of the application of sterilization will help ensure safety from the invisible but deadly world of microbial pathogens. The present article reviews the various recent sterilization protocols about orthodontic instrumentation and armamentarium and along with the general infection control measures.

Keywords: sterilization, infection control, COVID19, orthodontist.

Copyright () 2020 The Author(s): This is an open-access article distributed under the terms of the Creative Commons Attribution 4.0 International License (CC BY-NC 4.0) which permits unrestricted use, distribution, and reproduction in any medium for non-commercial use provided the original author and source are credited.

\section{INTRODUCTION}

Coronavirus disease 2019 (COVID-19) is a contagious disease caused by severe acute respiratory syndrome coronavirus (SARS-CoV-2). It emerged as a global pandemic in early 2020, affecting more than 200 countries and territories. The infection is highly contagious, with disease transmission reported from asymptomatic carriers, including children. It spreads through person-to-person contact via aerosol and droplets. The practice of social distancing - maintaining a distance of 1-2 m or $6 \mathrm{ft}$ - between people has been recommended widely to slow or halt the spread. In orthodontics, this distance is difficult to maintain, which places orthodontists at a high risk of acquiring and transmitting the infection [1].

Infection control is crucial for orthodontists and for patient health. The concept of sterilization and disinfection was introduced into the dental practice with the recognition of hepatitis $\mathrm{B}$ as an occupational disease in 1975, and considerable steps have been taken in infection control procedures with increasing prevalence of human immunodeficiency virus (HIV)/acquired immune deficiency syndrome (AIDS) in the mid-1980s [2].

The present article reviews the various recent sterilization protocols about orthodontic instrumentation and armamentarium and along with the general infection control measures.

\section{Primary Goals of Infection Control in Dental Clinic}

- To lower the risk of contamination by reducing the level of pathogens.

- To correct any break in aseptic technique.

- To use universal precautions with every patient (treat every patient and instrument as potentially infective).

- To protect patients and personnel from occupational infection [3].

\section{Definitions}

Sterilization is a process by which an article, medium or surface is freed from all the pathogenic micro-organisms either in vegetative or spore form

Disinfection- Disinfection is the process of destroying or inhibiting most pathogenic microorganisms and inactivating some viruses, hence reducing microbial contamination to the safety level.

\section{Infection control measures in orthodontic clinic}

1. Patient's history: During the initial appointment, a detailed and complete medical history to be taken from the patient, and in subsequent visits, updated accordingly.

2. Use of personal protective equipmentOrthodontist does not perform oral surgery, 
however, they should wear a lab coat, face mask and hand gloves as a general precautionary measure. Disposable gowns, surgical masks, protective eyeglasses and plastic face masks should be worn during procedures that are likely to splash blood, saliva and oral fluids [4]. As a result of the pandemic, the routine use of complete personal protective equipment may be advisable. Eventhough this equipment, that's usefulness is unquestionable, is very uncomfortable in the dayto-day clinical activity and also hinders psychological interaction with the patient-a fundamental tool in the treatment of children and adults [1].

3. Washing and care of hands- Before gloving- to remove transient micro-organisms to suppress residual micro-flora while wearing the gloves. After glove removal- to remove micro-organisms, which may have penetrated the gloves through microscopic defects or tears to reduce any residual micro-flora build up that may have occurred. Hand washing should be performed for about 40-45 seconds for performing routine orthodontic procedures. Hands should be dried with hot air or disposable paper towels, and should be followed by the use of disposable gloves [3].

4. Cleaning and sterilization procedures- thorough cleaning and sterilization of instruments and other supplies, which are routinely carried out in dental offices and the operating area such as chair, table, light handles, spittoon, three-way syringes etc., should be wiped frequently with $70 \%$ isopropyl alcohol after every patient. ${ }^{3}$ During the pandemic it has been considered paramount to implement other systematic cleaning protocols between patients regarding the waiting room furniture, toilets, floors, and other surfaces. These new protocols will probably continue to be applied, at least partially, in the future, even if they slow down the pace of practice [1].

5. Minimize the use of aerosol generating procedures-Many orthodontic procedures such as the bonding and debonding of brackets and attachments generate a substantial amount of aerosols which, in turn, pose potential risks of infection transmission. Depending on the size of the office, it will be advisable to designate an isolated and adequately equipped space to carry out those procedures that require the use of rotatory instruments as handpieces or ultrasonic scalers [5].

6. Immunization-is crucial that the orthodontist and the dental staff must be vaccinated against tuberculosis, rubella, diphtheria, tetanus and most importantly, against HBV [4].

\section{Sterilization/disinfection of different material and instruments used in orthodontic clinic Instruments}

Instruments used in orthodontics can be of three categories according to Spaulding system: a) Critical: - Instruments that penetrate the mucosa should be sterilized. E.g. Molar bands, band remover plier, band pinching pliers, mini-implant placement kit etc.

b) Semi Critical: - Instruments that touch the mucosa should be sterilized whenever possible or treated with high-level disinfectants. E.g. Most of the orthodontic instruments, intra-oral

mirrors, cheek retractors, and dental hand pieces, etc.

c) Least Critical: - Instruments that do not come in contact with mucous membrane such as bracket positioners, arch-forming pliers, torquing keys, bracket positioning gauges, bird beak plier etc. should be disinfected [6].

\section{Disinfection of Orthodontic Brackets}

Reuse of the orthodontic brackets is not advisable because it affects the clinical performance of the brackets and also increases the chances of infection. Speera et al., did a study to evaluate the effect of $0.01 \%$ chlorhexidine disinfectant solution on bond strength of metal and ceramic brackets and concluded that chlorhexidine does not have a significant effect on the metal and ceramic brackets adhesion ability. Thus, chlorhexidine is the recommended disinfectant for metal and ceramic brackets [7].

\section{Disinfection of Orthodontic Bands}

Stainless steel bands of various sizes are frequently used on molars during fixed orthodontic treatment. Choosing the appropriate size requires often several trials. If trying of the bands is attempted inside the patient's mouth and determined that the size is not appropriate, the band should be decontaminated from saliva and blood, and autoclaved for future use. There is currently little information about the contamination level and the disinfection procedure's success of the bands that are to be reused. Fulford et al., suggested that bacterial multiplication is not observed on the bands that are exposed to enzymatic disinfectant prior to autoclave sterilization [9].

Glass bead sterilizer has been shown to produce equally effective sterilization as that of autoclave $[10,11]$. The recommended protocol for sterilization of single molar band is $220^{\circ} \mathrm{C}$ for 5 seconds. If more than one band is placed at the same time the amount of time required is doubled. Other techniques for disinfecting bands, such as a 5-second tap water rinse, 10-second soap scrub, 30-minute immersion in alcohol, and alcohol flame, were ineffective in killing bacteria or spores. However, alcohol flames were effective in preventing growth on orthodontic molar bands inoculated with staphylococcus albus [12].

\section{Orthodontic Pliers}

If cross-infection prevention is to be taken seriously in orthodontics (bearing in mind the increasing number of adult patients being treated), then 
Sharath Kumar Shetty et al., Sch J Dent Sci, Dec, 2020; 7(12): 365-370

probably all instruments should be routinely sterilized using an autoclave. Some studies have showed that routine autoclaving of orthodontic pliers using a centralized system does not causes any more damage than chair side cold disinfection. This study suggested that chromed instruments are probably to be preferred to stainless steel as regards the pliers maintaining their 'looks' and keeping corrosion to the minimum [13]. A study by Andrea Wichelhaus et al., showed that heat sterilization caused less corrosion than chemical sterilization [14].

Corrosion resistance-Prior to dry-heat sterilization, if water drops or excess disinfectant is left on the pliers they can be severely damaged. Corrosion of these instruments is one of the few sterilization consequences that orthodontists face [3].

Precleaning and drying before autoclaving is recommended for orthodontic pliers.

\section{Orthodontic Archwires}

Orthodontic wires are frequently packaged in individual sealed bags in order to avoid crosscontamination. The instructions on the wrapper generally advise autoclave sterilization of the package and its contents if additional protection is desired. According to Pernier et al., utoclave sterilization had no adverse effects on the surface parameters or on the selected mechanical properties based on their study on stainless steel, nickel titanium and TMA wires [15].

\section{Elastomeric Ligatures}

Polyurethane elastomers are used in orthodontics in the form of ligatures and chains or modules. Numerous studies have been conducted to evaluate their strength, in terms of force delivery and rate of force decay in various environments and different testing condition. A limited number of studies testing the effect of antibacterial solutions on orthodontic elastomers appear in the literature. Mayberry et al., measured the force required to stretch three brands of modules a prescribed distance after 20 cyclic exposures of 10 minutes to a $0.5 \%$ glutaraldehyde solution, in addition to testing after other disinfection procedures. They found a slight weakening of the modules [16]. Jeffries and von Fraunhofer examined the tensile force to fail of six elastomeric chains exposed to two brands of $2 \%$ alkaline glutaraldehyde solution for 30 minutes, 10 hours, and 144 hours. Compared to as-received material, they found a significant decrease in failure load in four of the chains after exposure to one brand for 10 hours. At 144 hours, all materials were significantly decreased in strength. Curiously, the other solution did not affect the failure load of the chains. In general, these studies show that exposure to disinfectant solution may result in a decrease in tensile strength and force delivery [17].

Disinfection of elastomeric ligatures in $5 \%$ glutaraldehyde solution is recommended, but literature shows that repeated disinfection of elastomeric ligatures can damage these ligatures.

\section{Mini Implants}

After removal of temporary devices, the recovered devices are usually discarded. However, economic factors have caused some clinicians to re-use implants or other medical devices that are meant to be disposable, like pacemakers, intra-aortic balloons, haemodialysis membranes, coronary angioplasty catheters and orthodontic brackets and wires [20-22]. In case of re-use, it is mandatory to ensure the sterility and mechanical qualities of the device [22]. Not all implants can be re-used, but metal implants, like those made from titanium may be more amenable to re-use because they can be mechanically and chemically cleaned and re-sterilized with potentially little or no loss of form or function [20]. A study on effect of Autoclaving on the Fracture Torque of Mini- implants Used for Orthodontic Anchorage concluded that the autoclave sterilization of the mini- implants did not affect their resistance to fracture; however, the mini- implants from different manufacturers presented with statistically significant differences in their resistance to fracture [24] mini-screws when they were sterilized up to 10 times indicate that sterilization bears no clinical relevance to stability. A study by Sercan Akyalcin et al., showed that sterilization bears no clinical relevance to stability even when they were sterilized up to 10 times.

\section{Removable Acrylic Appliance}

When using removable appliances, there is an excessive formation of a biofilm layer that is observed on the retentive areas of hooks and springs, and on the smooth acrylic surfaces of the appliance. Studies showed that Lactobacillus and Streptococcus mutans levels are increased inside dental biofilm as a result of changing oral micro flora during orthodontic therapy with active removable appliances. Toothbrushes were not efficient enough to remove the microorganisms on the retentive areas of the appliances. Hence, it is recommended to use antimicrobial agents to eliminate the bacterial biofilm. Disinfection methods of acrylic orthodontic appliances should inactivate pathogenic microorganisms immediately, without damaging the composition of the appliance [9]. Soaking the appliance in a chemical solution could cause decomposition of the acrylic resin molecules [26]. In Lessa et al., [27] study, chlorhexidine gluconate, cetilpyridinium chloridine and sterile water were compared in terms of their eliminating action on Streptococcus mutans. Antimicrobial solutions in spray form were used, and they were examined for causing any changes in the composition of acrylic or not. The results of this study suggested that both of the previously mentioned antimicrobial agents reduced contamination compared to sterile water, but chlorhexidine gluconate was found to be significantly more effective than cetilpyridinium chloridine [27]. 


\section{Impression}

Dental impression materials can act as vectors transmitting a significant amount of microorganisms. Sodium hypochlorite disinfection is an efficient disinfection method for alginate impressions. Tap water rinsing reduces microbial load but does not eliminate the cross-infection potential of alginate [28]. The British Dental Association in the Health Technical Memorandum 01-05 recommends disinfection and decontamination of dental impressions before dispatching them to the dental laboratories, and states that the responsibility for ensuring dental impressions are both disinfected and labelled as such before being sent to dental laboratory lies solely with the dentist who should inform the dental lab technicians about the status of impression disinfection. Dental impressions contaminated with patient's saliva and blood may cross infect the dental casts poured from them. Rinsing the impression with water solely does not remove contamination, therefore disinfecting of the impression and further rinsing the disinfectant off is required [29].

\section{Surface and air disinfection in dental clinic}

Surfaces that cannot be sterilized must be disinfected effectively. These surfaces include the airwater sprayers, aspirator heads, reflector arms, cuspidors, drawers, head rest and arms.

Suitable clinic and instrument setting will reduce the surfaces to be disinfected. If the chair's positions can be controlled using a pedal and cuspidors controlled by buttons at the level of the elbow or the knee, hand contact is therefore minimized. Sodium hypochlorite $1 \%$ or solutions including $70 \%$ alcohol are used for surface disinfection in orthodontic clinics. Iodine solutions used for disinfection are cheap, easily stored and highly effective. The only disadvantage is the staining characteristic of iodine. There are types that can be diluted in water or in $70 \%$ isopropyl alcohol [6].

Various devices/ methods, including ventilation system, ultraviolet lamps, high-volume evacuator, automated room disinfection systems with hydrogen peroxide vapor (fumigation) are used for room surfaces and air disinfection [30-32].

\section{Ozone Generators}

Air ozonizer (ozonator) is a device, in which ozone is formed under the influence of electric current that has a strong disinfecting effect. Ozonators eradicate bacteria, viruses, fungi, and their spores.

\section{Advantages}

- Strong decontamination of air, removal of inhalation allergens, and unpleasant odors

\section{Disadvantage}

- They form nitrogen oxides causing destructive and discoloring effect on plastic elements and rubber structures, e.g., gaskets.
- Cannot be used together with other disinfection devices, such as UV lamps

\section{Fogging Equipment}

These devices can utilize different substances for spraying, such as hydrogen peroxide, chlorine dioxide, and a mixture of peracetic acid with hydrogen peroxide. Hydrogen peroxide generators are widely used for dental offices disinfection [34, 35].

Advantages:

- Short disinfection procedure with about 10 minutes on average, and short ventilation time after fumigation with about 30 minutes (time depends on the concentration of fumigation agent).

- Strong decontamination effect.

- Safe for medical and electronic devices (minimal increase in air humidity).

- $\quad$ Low cost (compressed air fumigators) [33].

Disadvantages:

- Quite high price (turbine fumigators).

- Low availability of stabilized hydrogen peroxide during the COVID-19 pandemic (it is essential to ask the distributors of fumigators whether they supply stabilized hydrogen peroxide)

- No medical staff can be in the room during the fumigation process. ${ }^{33}$

\section{Ultraviolet Lamps}

UV-C radiation is a result of low-pressure mercury discharges (germicidal radiators). During the operation of these devices, a UV-C electromagnetic wave, with length ranging between 250 and $270 \mathrm{~nm}$, is generated. The bactericidal mechanism of UV-C lamps is evoked by DNA damage [33].

Advantages:

- Easy disinfection procedure [33].

Disadvantages:

- No destruction of spores larger than many bacteria and viruses [33].

- Highly resistant to Ultraviolet germicidal irradiation

- No effect on dust mites and allergens,

- To get a bactericidal effect, the lamp should be turned on for many hours,

- $\quad$ Disinfecting effects on surfaces are obtained after 8 hours of continuous application,

- Staying in the room while the UV-C lamp is working is forbidden. ${ }^{33}$

\section{Conventional Air Filtration System}

Ultra-low particulate air (ULPA) and highefficiency particulate air (HEPA) filters capture particles from the air stream, but HEPA filters initially retain larger clusters of bacteria. Still, after a while, a single bacterium is released, which starts to replicate. 
Moreover, the small size of holes in the ULPA filters requires more pressure and energy needed to run the system. HEPA filtration is often used in combination with other technologies. By retention of the pathogens, filters create a localized biological hazard, which is why they need to be replaced regularly [33].

Advantages:

- Possibility of continuous operation, filtration of particles larger than $0.3 \mu \mathrm{m}$ [33].

Disadvantages:

- Colonization of filters is a common problem of physical filters since they capture rather than destroy bacteria and fungi. Also, filters are a good medium for the growth of bacteria and fungi because of captured dust and other organic particles.

- Trapped atmospheric dust can serve as a nutrient for fungi and this process can transform the filter into a secondary source of pollution.

- HEPA filtration does not capture or kill viruses [33].

\section{CONCLUSION}

Covid 19 disease has altered the entire dental community. In todays orthodontic practice, disease control must undergo major reevaluation and restructuring. Effective infection control must be a routine component of professional activity. Thorough understanding of the application of sterilization will help ensure safety from the invisible but deadly world of microbial pathogens. Always "Prevention is better than cure".

\section{REFERENCES}

1. García-Camba P, Marcianes M, Morales MV. Changes in orthodontics during the COVID-19 pandemic that have come to stay. American Journal of Orthodontics and Dentofacial Orthopedics. 2020 Oct 1;158(4):e1-3.

2. Çelikel AD, Ekmekçioğlu H, Külekçi G, Fıratlı S. Evaluation of the Compliance of Orthodontists to Infection Control Procedures in Turkey. Turkish journal of orthodontics. 2018 Jun;31(2):37.

3. Shilpa K. Infection control in orthodontics. Journal of Orthodontics and Endodontics. 2015(1):1-12.

4. Starnbach HO, Biddle PA. A pragmatic approach to asepsis in the orthodontic office. The Angle Orthodontist. 1980 Jan;50(1):63-6.

5. Ge ZY, Yang LM, Xia JJ, Fu XH, Zhang YZ. Possible aerosol transmission of COVID-19 and special precautions in dentistry. J Zhejiang Univ Sci B. 2020; 21:361-8.

6. Spaulding EH. Chemical disinfection of medical and surgical materials. In: Lawrence C, Block SS, editors. Disinfection, sterilization, and preservation. Philadelphia: Lea and Febiger. 1968:517-531.
7. Speera C, Zimny D, Hopfenmueller W, Holtgrave EA. Bond Strength of Disinfected Metal and Ceramic Brackets. Angle Orthod. 2005;75:836-42.

8. Mulick JF. Upgrading sterilization in the orthodontic practice. American Journal of Orthodontics. 1986 Apr 1;89(4):346-51.

9. Benson and Douglas. Sterilization and Disinfection in Orthodontics. Intech Open. 2007.

10. Ray S, Chopra SS, Mitra R, Jain A. Reliability of glass bead sterilization for tried-in orthodontic bands. Journal of Indian Orthodontic Society. 2011 Dec;45(4):189-92.

11. Benson PE, Douglas CW. Decontamination of orthodontic bands following size determination and cleaning. Journal of orthodontics. 2007 Mar $1 ; 34(1): 18-24$.

12. Smith GE. Glass bead sterilization of orthodontic bands. American Journal of Orthodontics and Dentofacial Orthopedics. 1986 Sep 1;90(3):243-9.

13. Jones ML. An initial assessment of the effect on orthodontic pliers of various sterilization/disinfection regimes. British journal of orthodontics. 1989 Nov;16(4):251-8.

14. Wichelhaus A, Brauchle G, Mertmann M, Sander FG. Corrosion of orthodontic pliers using different sterilization procedures. Journal of Orofacial Orthopedics/Fortschritte der Kieferorthopädie. 2004 Nov 1;65(6):501-11.

15. Pernier C, Grosgogeat B, Ponsonnet L, Benay G, Lissac M. Influence of autoclave sterilization on the surface parameters and mechanical properties of six orthodontic wires. The European Journal of Orthodontics. 2005 Feb 1;27(1):72-81.

16. Mayberry D, Allen R, Close J, Kinney DA. Effects of disinfection procedures on elastomeric ligatures. Journal of clinical orthodontics: JCO. 1996 Jan;30(1):49.

17. Jeffries CL, Von Fraunhofer JA. The effects of $2 \%$ alkaline gluteraldehyde solution on the elastic properties of elastomeric chain. The Angle Orthodontist. 1991 Mar;61(1):26-30.

18. Andreasen GF, Bishara S. Comparison of alastik chains with elastics involved with intra-arch molar to molar forces. The Angle Orthodontist. 1970 Jul;40(3):151-8.

19. Evangelista MB, Berzins DW, Monaghan P. Effect of disinfecting solutions on the mechanical properties of orthodontic elastomeric ligatures. The Angle Orthodontist. 2007 Jul 1;77(4):681-7.

20. Schwartz Z, Lohmann CH, Blau G, Blanchard CR, Soskolne AW, Liu Y, Cochran DL, Dean DD, Boyan BD. Re- use of implant coverscrews changes their surface properties but not clinical outcome. Clinical oral implants research. 2000 Jun;11(3):183-94.

21. Sonis AL. Air abrasion of failed bonded metal brackets: a study of shear bond strength and surface characteristics as determined by scanning electron microscopy. American Journal of 
Orthodontics and Dentofacial Orthopedics. 1996; 110(1):96-98.

22. Pringle RA, Leman RB, Kratz JM and Gillette PC. An argument for pacemaker reuse: pacemaker mortality in 169 patients over ten years. Pacing and Clinical Electrophysiology. 1986; $9(6$ Pt2):1295-1298.

23. Grimandi G, Sellal O, Grimandi F, Crochet D. Risks of reusing coronary angioplasty catheters: results of an experimental study. Catheterization and Cardiovascular Diagnosis. 1996(2); 38:123130

24. Mattos CT, Ruellas AC, Sant'Anna EF. Effect of autoclaving on the fracture torque of miniimplants used for orthodontic anchorage. Journal of orthodontics. 2011 Mar;38(1):15-20.

25. Akyalcin S, McIver HP, English JD, Ontiveros JC, Gallerano RL. Effects of repeated sterilization cycles on primary stability of orthodontic miniscrews. The Angle Orthodontist. 2013 Jul;83(4):674-9.

26. Amitha H, Munshi AK. Effect of Chlorhexidine Gluconate Mouthwash on the Plaque Microflora in Children Using Intraoral Appliances. J Clin Pediatr Dent. 1995; 20:23-9.

27. Lessa FCR, Enoki C, YokoIto I, Faria G, Matsumoto MAN, Filho PN. In-vivo Evaluation of the Bacterial Contamination and Disinfection of Acrylic Baseplates of Removable Orthodontic Appliances. Am J Orthod Dentofacial Orthop. 2007; 131:705.e11-705.e17.

28. Correia-Sousa J, Tabaio AM, Silva A, Pereira T, Sampaio-Maia B, Vasconcelos M. The effect of water and sodium hypochlorite disinfection on alginate impressions. Revista Portuguesa de Estomatologia, Medicina Dentária e Cirurgia Maxilofacial. 2013 Jan 1;54(1):8-12.

29. Al Mortadi N, Al-Khatib A, Alzoubi KH, Khabour OF. Disinfection of dental impressions: knowledge and practice among dental technicians. Clinical, cosmetic and investigational dentistry. 2019;11:103.

30. Otter JA, Donskey C, Yezli S, Douthwaite S, Goldenberg S, Weber DJ. Transmission of SARS and MERS coronaviruses and influenza virus in healthcare settings: the possible role of dry surface contamination. Journal of Hospital Infection. 2016 Mar 1;92(3):235-50.

31. Meng L, Hua F, Bian Z. Coronavirus Disease 2019 (COVID-19): emerging and future challenges for dental and oral medicine. J Dent Res. 2020; 99:481-487.

32. Harrel SK, Molinari J. Aerosols and splatter in dentistry: a brief review of the literature and infection control implications. J Am Dent Assoc. 2004; 135:429-437.

33. Matys J, Grzech-Leśniak K, Dominiak M. Disinfectants and devices for surface and air disinfection in dental offices. Journal of Stomatology. 2020 Aug 30;73(4):200-5.

34. Rogers JV, Choi YW. Inactivation of Francisella tularensis Schu S4 in a biological safety cabinet using hydrogen peroxide fumigation. Appl Biosaf. 2008; 13:15-20.

35. Tanaka S, Abuku S, Seki Y, Imamiya S. Evaluation of methyl bromide exposure on the plant quarantine fumigators by environmental and biological monitoring. Ind Health. 1991; 29:11-21. 